\title{
Article \\ Bilateral Choanal Atresia and Endoscopic Surgery: A Chance for CHARGE Patients
}

\author{
Maria Baldovin $1, *,+\left(\mathbb{D}\right.$, Diego Cazzador ${ }^{1,+}+\mathbb{C}$, Claudia Zanotti ${ }^{1}$, Giuliana Frasson ${ }^{2}$, Athanasios Saratziotis ${ }^{3}$, \\ Fabio Pagella ${ }^{4}$, Stefano Pelucchi ${ }^{5}$ and Enzo Emanuelli ${ }^{1}$
}

check for

updates

Citation: Baldovin, M.; Cazzador, D.; Zanotti, C.; Frasson, G.; Saratziotis,

A.; Pagella, F.; Pelucchi, S.; Emanuelli,

E. Bilateral Choanal Atresia and

Endoscopic Surgery: A Chance for CHARGE Patients. J. Clin. Med. 2021, 10, 2951. https://doi.org/10.3390/ jcm10132951

Academic Editors: Emmanuel Andrès and Michael Setzen

Received: 26 April 2021

Accepted: 26 June 2021

Published: 30 June 2021

Publisher's Note: MDPI stays neutra with regard to jurisdictional claims in published maps and institutional affiliations.

Copyright: (c) 2021 by the authors. Licensee MDPI, Basel, Switzerland. This article is an open access article distributed under the terms and conditions of the Creative Commons Attribution (CC BY) license (https:/ / creativecommons.org/licenses/by/ $4.0 /$ )
1 Department of Neurosciences, Section of Otorhinolaryngology, University of Padova, 35128 Padova, Italy; diego.cazzador@unipd.it (D.C.); zanotti.claudia89@gmail.com (C.Z.); enzoemanuelli@libero.it (E.E.)

2 Unit of Otorhinolaryngology, Ospedale di Cittadella, 35013 Cittadella, Italy; giuliana.frasson@hotmail.it

3 Department of Otolaryngology, Head and Neck Surgery, University Hospital of Larissa, 41110 Larissa, Greece; asaratziotis@gmail.com

4 ENT Department, I.R.C.C.S. Policlinico San Matteo-University of Pavia, 27100 Pavia, Italy; tpagella@libero.it

5 ENT \& Audiology Unit, Department of Neuroscience and Rehabilitation, University Hospital of Ferrara, 44124 Ferrara, Italy; stefano.pelucchi@unife.it

* Correspondence: maria.baldovin@gmail.com; Tel.: +39-049-821-8776

+ The first two authors contributed equally to the present study.

\begin{abstract}
Bilateral choanal atresia (CA) is a rare congenital malformation frequently associated with other anomalies. CHARGE association is closely linked to bilateral CA. The aim of this study was to describe the outcomes of the endoscopic repair in bilateral CA, and to assess the role of postoperative nasal stenting in two cohorts of CHARGE-associated and non-syndromic CA. Thirty-nine children were retrospectively analyzed (16 patients had CHARGE-associated CA). The rate of postoperative neochoanal restenosis was $31.3 \%$ in the CHARGE population, and $47.8 \%$ in the non-syndromic CA cohort. Data on postoperative synechiae and granulation tissue formation, need for endonasal toilette and dilation procedures, and number of procedures per patient were presented. Stent positioning led to a higher number of postoperative dilation procedures per patient in the non-syndromic cohort $(p=0.018)$, and to a higher rate of restenosis both in the CHARGE-associated, and non-syndromic CA populations. Children with CHARGE-associated and non-syndromic bilateral CA benefitted from endonasal endoscopic CA correction. The postoperative application of an endonasal stent should be carefully evaluated.
\end{abstract}

Keywords: choanal atresia; bilateral; CHARGE association; endoscopic surgery; stent; postoperative outcomes; restenosis; neonatal and pediatric airway disorders; nasal obstruction; congenital malformations

\section{Introduction}

In 1979, Hall described 17 children with choanal atresia (CA) and multiple congenital anomalies [1], and Hittner reported on 10 children with ocular colobomas and multiple congenital anomalies, including CA. This association was called "Hall-Hittner syndrome" [2]. In 1981, Pagon et al. coined the acronym CHARGE to describe patients with coloboma, heart defect, CA, retarded growth and mental development, genital hypoplasia, and ear anomalies/deafness [3]. Because of the heterogeneous clinical presentation, in 1998, Blake et al. described four major criteria (the classical 4C's: Choanal atresia, Coloboma, Characteristic ears, and Cranial nerve anomalies), and minor characteristics (genital hypoplasia, developmental delay, cardiovascular malformations, growth deficiency, orofacial cleft, tracheoesophageal fistula, and distinctive face) to define the new entity. Recently, some authors have proposed the inclusion of pathogenic CHD7 variant status as a major criterion [4]. Even if CHD7 mutation-positive and -negative patients do not differ in their chance of presenting CA [5], this condition has been reported in between $36 \%$ and $65 \%$ of cases $[6,7]$, and frequently CA is bilateral. Otolaryngologists are involved in the treatment 
of several conditions in CHARGE patients, including hearing loss, inner ear malformations, and CA [8-11].

The endoscopic endonasal approach currently represents a widely accepted treatment modality for CA repair [12]. However, the use of a stent as an ancillary procedure after surgical CA correction is still debated. Literature regarding CA in CHARGE patients is scarce [13-18]. Up to now, no studies have compared stenting and non-stenting strategies for the surgical treatment of CA in the CHARGE population.

The aim of this study was to describe the outcomes of endoscopic CA repair in a population of patients with CHARGE association and in non-syndromic patients diagnosed with bilateral CA, as well as to assess the role of nasal stenting.

\section{Materials and Methods}

\subsection{Selection of Patients}

Between January 2001 and January 2016, 74 children diagnosed with congenital CA were managed at the Unit of Otolaryngology of the University of Padova. One patient was lost to follow-up, and in six cases details about first surgery were not available, resulting in seven patients excluded from the study (Figure 1).

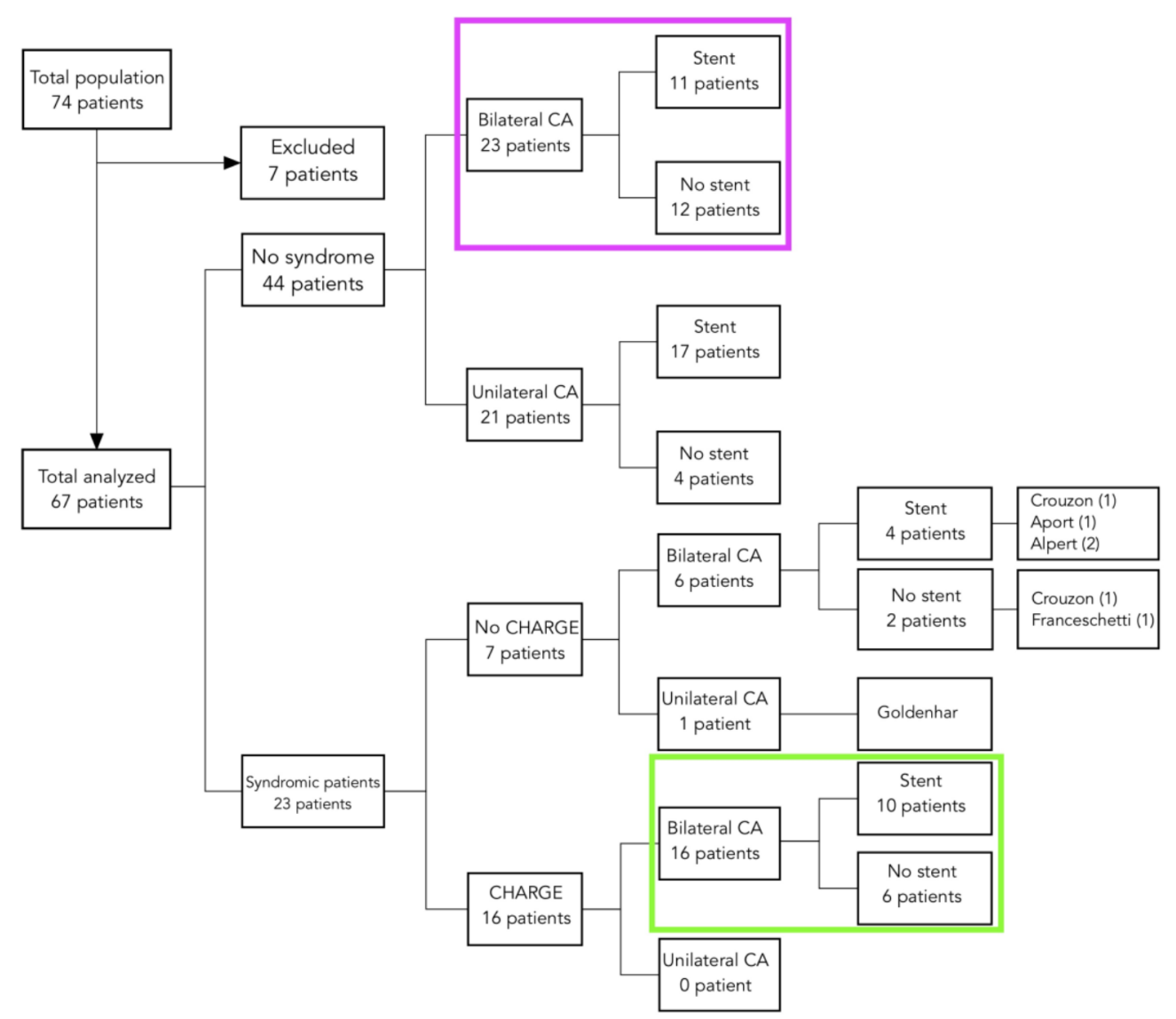

Figure 1. Diagram showing the overall population divided according to the association with syndromic conditions, laterality of the atresia, and stenting. Colored squares indicate the study populations. CA, choanal atresia.

This retrospective study included 39 children, 16 (41.0\%) with diagnosis of CHARGEassociated bilateral CA and 23 (59.0\%) with non-syndromic bilateral CA. Seventeen patients $(43.6 \%)$ came to our institution for relapse of a previous surgical repair performed elsewhere.

Data were examined in accordance with Italian privacy and sensitive laws (D. Lgs. 196/03). Before surgery, all patients' parents signed a detailed informed consent form 
and gave their written permission for clinical case publication. The diagnostic work-up included rigid/flexible video-rhino-laryngoscopy and computed tomography (CT) of the head.

\subsection{Surgical Endoscopic Technique}

Surgical procedures were performed under general anesthesia through an endoscopic approach in all cases, with $0^{\circ}$ endoscopes $(2.7$ or $4 \mathrm{~mm}$ ) connected to a high-definition camera and a monitor. Mucosal decongestion was induced by applying cotton pledges soaked in $5 \mathrm{~mL}$ of xylometazoline and $2 \mathrm{~mL}$ of lidocaine in $10 \mathrm{~mL}$ of saline solution with or without 1:100.000 epinephrine solution. Hegar's dilators were used to puncture the atretic plate. The technique of mucoperiosteal flaps, shown in Figure 2, consisted of a star-shaped incision of the nasal mucosa at the junction between the vomer and the atretic plate to elevate the mucoperiosteal flap. The inferomedial portion of the atretic plate was drilled out with a skeeter, and the infero-posterior part of the vomer was resected with backbiting forceps. The anterior mucoperiosteal flap was used to cover the raw bony areas on the lateral wall of the nasal fossa and pterygoid plates. The mucosal flap of the nasopharyngeal side of the atretic plate resurfaced the medial side of the neochoana and the septum.

\section{Stent}

After surgical atresia correction, the use of stents was not routinely performed. In the case of choanal stenting, " $\mathrm{U}$ "-shaped endotracheal tubes 3.0-3.5 (Portex Ltd., Kent, UK) were employed and positioned through the neochoana with an anterior fixation at the columella. In the nasopharyngeal portion of the stent, three to four holes were created to allow breathing and postoperative irrigation.

\subsection{Follow-Up and Postoperative Outcomes}

Follow-up consisted of endonasal medications under sedation and local anesthesia, performed at days 7 and 14 after surgery. When no further medications under sedation were needed, office endoscopic evaluations were indicated at 45 and 90 postoperative days, then after six months and yearly.

The postoperative outcomes were the rate of restenosis, synechiae, and granulation tissue formation and the rate of toilettes and dilations procedures performed after surgery. The neochoana was considered restenosed in the case of total occlusion. Patency was defined if the neochoana lumen was wider than $50 \%$. The toilette procedure consisted of removing debris and fibrinous tissue through aspiration or Weil forceps. For younger patients, this was performed under general anesthesia, while for collaborative children, performed under local anesthesia. The median follow-up was 26.5 months (IQR 12.5-50.5).

\subsection{Analysis}

Fisher's exact test was used for comparison of categorical variables, while MannWhitney $U$-test was applied to compare continuous variables. Statistical significance was set at $p<0.05$. Analyses were performed with SPSS, version 20 (Statistical Package for the Scientific Sciences, SPSS Inc., Chicago, IL, USA). 


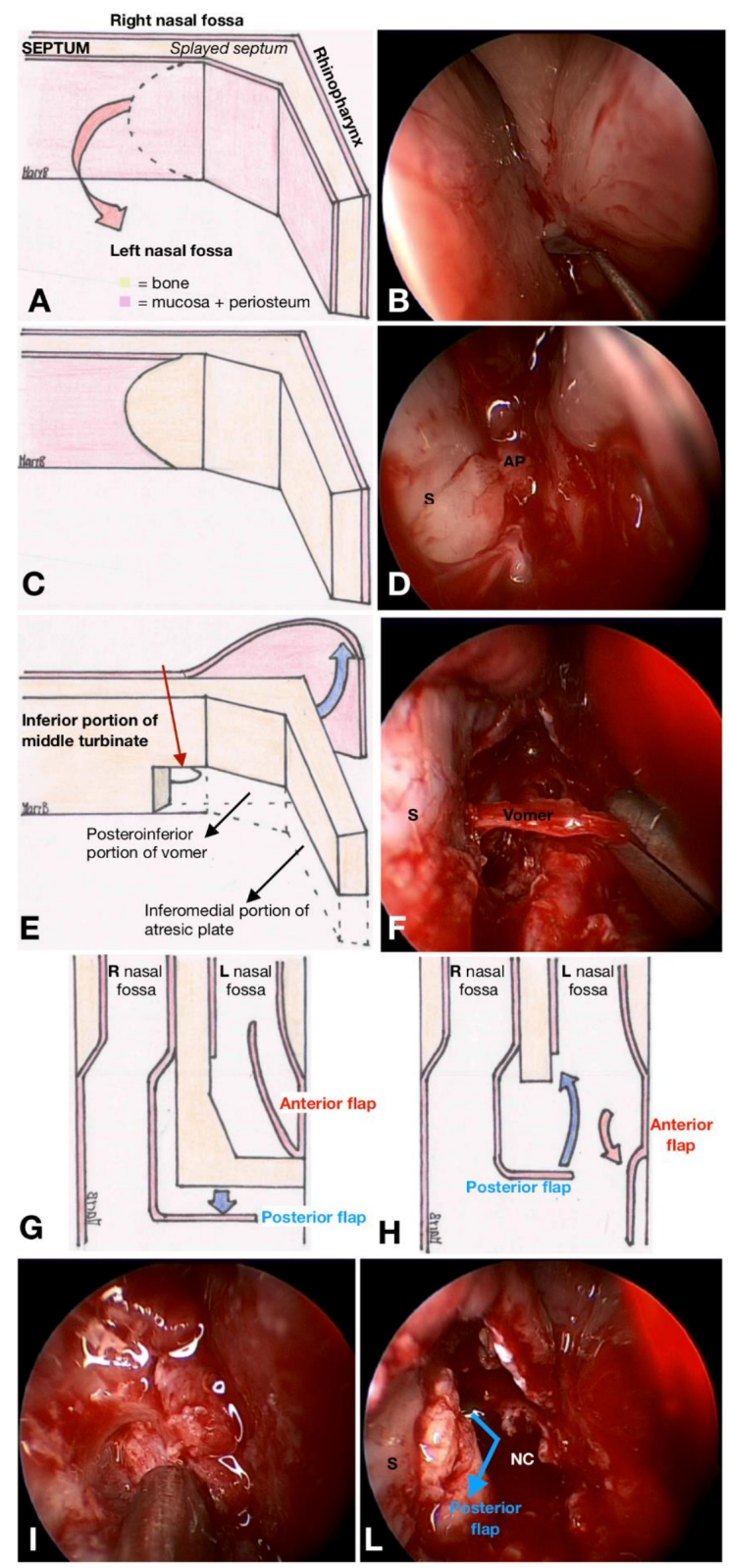

Figure 2. The mucoperiosteal flap technique. (A) Drawing of a left choanal atresia (CA). Dashed line indicates the incision made for harvesting the anterior mucoperiosteal flap, to be positioned to cover the lateral wall of the nasal cavity thereafter. An equivalent endoscopic image is shown in (B). (C,D) The subperiosteal plane evidenced after mucoperiosteal flap removal. (E) Drawing of the posterior mucoperiosteal flap created on the nasopharyngeal side of the contralateral nasal fossa, flipped contralaterally (blue arrow). Dashed lines underline the bony portion of the atretic plate. The inferior portion of the middle turbinate of the contralateral nasal fossa represents the anterior landmark for the posterior margin of vomer resection (thin red arrow). (F) Endoscopic view of the vomer resection. $(\mathbf{G}, \mathbf{H})$ Repositioning of the harvested flaps in the neochoana. The anterior flap (both in cases of unilateral and bilateral CA) covers the lateral wall of the nasal fossa; the posterior flap (in unilateral CA) resurfaces the free margin of the vomer bone ( $\mathrm{L}=$ left; $\mathrm{R}=$ right). (I,L) Equivalent endoscopic views. (I) Nasopharyngeal mucosal plane observed after removing the atretic plate. (L) After anterior replacement (blue arrow), the posterior mucoperiosteal flap harvested on the nasopharyngeal side of the CA covers the posterior edge of the vomer $(S=$ septum; $\mathrm{AP}=$ atretic plate). 


\section{Results}

All 39 patients included in the study were diagnosed with bilateral CA. The patients' characteristics and data regarding stent positioning are presented in Table 1. The surgical outcomes adjusted for CHARGE association are summarized in Table 2. In the CHARGE population, $31.3 \%$ patients developed neochoanal restenosis, $18.8 \%$ had synechiae, and $31.3 \%$ granulation tissue development. The restenosis rate in non-syndromic-associated CA was $47.8 \%$, while synechiae and granulation tissue were diagnosed in $26.1 \%$ and $60.9 \%$ of the patients, respectively. No significant differences were observed between the two study populations, nor in terms of postoperative outcomes, neither concerning the rate or the number of postoperative procedures per patient.

Table 1. Demographic characteristics and data of the study cohort.

\begin{tabular}{lcc}
\hline & CHARGE-Associated CA & Non-Syndromic CA \\
\cline { 2 - 3 } & $\boldsymbol{n = 1 6}$ & $\boldsymbol{n}=\mathbf{2 3}$ \\
\hline Age (days), median (IQR) & $5(3-83)$ & $15(2.5-165)$ \\
Sex & & \\
$\quad$ Male & $5(31.3 \%)$ & $10(43.5 \%)$ \\
$\quad$ Female & $11(68.7 \%)$ & $13(56.5 \%)$ \\
Stent & $6(37.5 \%)$ & $11(47.8 \%)$ \\
$\quad$ No & $10(62.5 \%)$ & $12(52.2 \%)$ \\
$\quad$ Yes & $42(41-46)$ & $41(31.5-42.5)$ \\
Stenting duration (days), median (IQR) &
\end{tabular}

$\mathrm{CA}$, choanal atresia; IQR, interquartile range.

Table 2. Postoperative outcome comparison between CHARGE-associated and non-syndromic bilateral choanal atresia.

\begin{tabular}{|c|c|c|c|}
\hline & CHARGE-Associated CA & Non-Syndromic CA & \multirow{2}{*}{$p$-Value } \\
\hline & $n=16$ & $n=23$ & \\
\hline Restenosis, $n(\%)$ & $5(31.3 \%)$ & $11(47.8)$ & 0.342 \\
\hline Synechiae, $n(\%)$ & $3(18.8 \%)$ & $6(26.1)$ & 0.711 \\
\hline Granulation tissue, $n(\%)$ & $5(31.3 \%)$ & $14(60.9)$ & 0.105 \\
\hline Toilettes, $n(\%)$ & $5(31.3 \%)$ & $10(43.5)$ & 0.517 \\
\hline Dilations, $n(\%)$ & $9(56.3 \%)$ & $17(73.9)$ & 0.312 \\
\hline \multicolumn{4}{|l|}{$\mathrm{N}^{\circ}$ of toilettes per patient } \\
\hline Mean (SD) & $0.93(2.31)$ & $0.78(1.24)$ & \\
\hline Median (IQR) & $0(0-1)$ & $0(0-1)$ & 0.637 \\
\hline \multicolumn{4}{|l|}{$\mathrm{N}^{\circ}$ of dilations per patient } \\
\hline Mean (SD) & $1.60(1.84)$ & $2.09(1.90)$ & \\
\hline Median (IQR) & $1(0-3)$ & $2(0-3)$ & 0.425 \\
\hline
\end{tabular}

$\mathrm{SD}$, standard deviation; IQR, interquartile range.

\subsection{Role of a Stent in CHARGE-Associated Choanal Atresia}

The surgical outcomes adjusted for postoperative stenting are summarized in Table 3. Overall, $31.3 \%$ patients developed a neochoanal restenosis, $18.8 \%$ synechiae, and $31.3 \%$ granulation tissue formation. No significant differences were calculated considering the rate of restenosis and the need for postoperative toilette and dilation procedures between the stented and non-stented patients $(40.0 \%$ vs. $16.7 \%, p=0.588 ; 30.0 \%$ vs. $33.3 \%, p=1.00$; $50.0 \%$ vs. $66.7 \%, p=0.633$, respectively). 
Table 3. Postoperative outcomes in CHARGE-associated choanal atresia according to stenting/nonstenting procedure.

\begin{tabular}{lccc}
\hline \multirow{2}{*}{ CHARGE-Associated CA } & Stent (S) & Non-Stent (NS) & S vs. NS \\
\cline { 2 - 4 } & $\boldsymbol{n}=\mathbf{1 0}$ & $\boldsymbol{n}=\mathbf{6}$ & $\boldsymbol{p}$-Value \\
\hline Restenosis, $n(\%)$ & $4(40.0)$ & $1(16.7)$ & 0.588 \\
Synechiae, $n(\%)$ & $2(20.0)$ & $1(16.7)$ & 0.868 \\
Granulation tissue, $n(\%)$ & $3(30.0)$ & $2(33.3)$ & 1 \\
Toilettes, $n(\%)$ & $3(30.0)$ & $2(33.3)$ & 1 \\
Dilations, $n(\%)$ & $5(50.0)$ & $4(66.7)$ & 0.633 \\
$\mathrm{~N}^{\circ}$ of toilettes per patient & & & \\
$\quad$ Mean (SD) & $0.40(0.70)$ & $1.67(3.61)$ & 0.955 \\
$\quad$ Median (IQR) & $0(0-1)$ & $0(0-1)$ & \\
$\mathrm{N}^{\circ}$ of dilations per patient & & & \\
$\quad$ Mean (SD) & $1.40(1.65)$ & $1.67(2.25)$ & 1 \\
$\quad$ Median (IQR) & $0(0-3)$ & $1(0-2)$ & \\
\hline
\end{tabular}

SD, standard deviation; IQR, interquartile range.

Although not statistically significant, the mean number of toilette procedures $(0.40 \pm 0.70$ vs. $1.67 \pm 3.61)$ and dilations $(1.40 \pm 1.65$ vs. $1.67 \pm 2.25)$ per patient was lower in the group with stent.

\subsection{Role of a Stent in Non-Syndromic Choanal Atresia}

The surgical outcomes adjusted for postoperative stenting are summarized in Table 4 . The rate of restenosis and granulation tissue formation was higher for the group with a stent placement than for patients without a stent $(63.6 \%$ vs. $33.3 \%, p=0.220$ and $81.8 \%$ vs. $41.7 \%, p=0.089$ ). Patients who underwent stent positioning required toilette and dilation procedures in $54.5 \%$ and $90.9 \%$ of cases, respectively. Although statistical significance was not reached, lower rates were observed for the patients without a stent $(33.3 \%$ and $58.3 \%$ of toilette and dilation procedures, respectively).

Table 4. Postoperative outcomes in non-syndromic bilateral choanal atresia according to stenting/non-stenting procedure.

\begin{tabular}{lccc}
\hline \multirow{2}{*}{ Non-Syndromic Bilateral CA } & Stent (S) & Non-Stent (NS) & S vs. NS \\
\cline { 2 - 4 } & $\boldsymbol{n}=\mathbf{1 1}$ & $\boldsymbol{n}=\mathbf{1 2}$ & $\boldsymbol{p}$-Value \\
\hline Restenosis, $n(\%)$ & $7(63.6)$ & $4(33.3)$ & 0.220 \\
Synechiae, $n(\%)$ & $1(9.1)$ & $5(41.7)$ & 0.155 \\
Granulation tissue, $n(\%)$ & $9(81.8)$ & $5(41.7)$ & 0.089 \\
Toilettes, $n(\%)$ & $6(54.5)$ & $4(33.3)$ & 0.414 \\
Dilations, $n(\%)$ & $10(90.9)$ & $7(58.3)$ & 0.155 \\
$\mathrm{~N}^{\circ}$ of toilettes per patient & $0.64(0.67)$ & $0.92(1.62)$ & \\
$\quad$ Mean (SD) & $1.0(0.0-1.0)$ & $0.0(0.0-1.5)$ & 0.74 \\
$\quad$ Median (IQR) & $2.91(1.81)$ & $1.33(1.72)$ & \\
$\mathrm{N}^{\circ}$ of dilations per patient & $2.0(2.0-4.0)$ & $1.0(0.0-2.0)$ & $0.018^{*}$ \\
$\quad$ Mean (SD) & &
\end{tabular}

Interestingly, stented patients needed a significantly higher number of dilations per patient, than non-stented patients $(2.0(2-4)$ vs. $1.0(0-2), p=0.018])$.

\section{Discussion}

The results obtained from this study demonstrated that the endoscopic technique is a valuable option for children with bilateral CA. The first endoscopic approach to treat CA was described by Stankiewicz in 1990 [19], who reported on four cases with detailed explanation of the surgical technique and the reasons for success and failure. In 
2000, an international survey of pediatric otolaryngologists belonging to the American Society of Pediatric Otolaryngology (ASPO) stated that $85 \%$ of the interviewees preferred the endoscopic approach for CA repair, even if transpalatal repair and puncture with Fearon dilators were still advocated by $60 \%$ and $17 \%$, respectively. This survey underlined controversies in the management of CA among the experts [20]. Approximately 20 years later, Moreddu et al. submitted to the members of the International Otolaryngology Group (IPOG) a questionnaire to establish expert recommendations on CA management and care [12]. Transnasal endoscopic repair was the preferred initial approach for CA repair, with $35.7 \%$ of the members adopting the mucosal flap technique. The transpalatal approach was applied when transnasal repair was prevented. Progressively, the use of a stent found less indication, and only in selected cases.

In non-syndromic bilateral CA, we obtained $66.7 \%$ vs. $36.4 \%$ success rates $(p=0.220)$ for the stented and non-stented groups, respectively. Compared to stented patients, a lower rate of non-stented patients underwent endonasal toilette procedures (33.3\% vs. $54.5 \%$, $p=0.414$ ) and dilations ( 58.3 vs. $90.9 \%, p=0.155)$, with a significantly lower mean number of dilations per patient $(1.33$, vs. $2.91, p=0.018)$

The low incidence of CA prevents designing a high level of evidence-based studies to address open issues. Systematic reviews with meta-analyses have thus been conducted, trying to clarify the debated use of a nasal stent after CA repair. Bedwell and Choi examined five studies, including 112 patients, with the aim of comparing outcomes between stented and non-stented patients. They affirmed that stent placement is not necessary after endoscopic surgical repair to obtain excellent postoperative outcomes and low complication rates [21]. Strychowsky's meta-analysis of 12 studies, including 215 patients, revealed no differences in terms of success rate between patients with and without a stent [22]. The only prospective randomized controlled study was designed by Tomoum et al. [23], which divided 72 patients into two groups according to the use of a stent. The postoperative outcomes were significantly better in the group without a stent.

This study included a cohort of 16 patients diagnosed with CHARGE association, all presenting with bilateral CA. The endoscopic approach proved to be an effective technique for the treatment of associated CA, ensuring in CHARGE patients a $68.7 \%$ postoperative success rate and a low incidence of synechiae and granulation tissue formation (31.3\%).

In literature, there are very few studies describing the outcomes of endoscopic CA repair in CHARGE association (Table 5). The results are hardly comparable, given the several surgical approaches included in the series $[13,14,24]$. More recent studies have described cases treated only with the endoscopic technique [15-18].

Table 5. Studies on choanal atresia repair in CHARGE association.

\begin{tabular}{|c|c|c|c|c|c|c|}
\hline Author, Year & $\begin{array}{c}\text { Patients } \\
n\end{array}$ & $\begin{array}{l}\text { Study Period } \\
\text { (Years) }\end{array}$ & $\begin{array}{l}\text { CHARGE } \\
n\end{array}$ & $\begin{array}{c}\text { Bilateral } \\
n\end{array}$ & $\begin{array}{l}\text { Endoscopic } \\
\text { Approach }\end{array}$ & $\begin{array}{l}\text { Outcome * } \\
\quad n,(\%)\end{array}$ \\
\hline Schraff et al., 2006 [13] & 57 & 1990-2005 & 14 & 9 & 10 & $4(40.0)$ \\
\hline Hengerer et al., 2008 [14] & 73 & 1973-2005 & 16 & na & 7 & $1(14.3)$ \\
\hline Sinha et al., 2016 [15] & 22 & 20 years & 8 & na & 8 & $\begin{array}{l}100 \% \text { mortality due to } \\
\text { CHARGE-related conditions }\end{array}$ \\
\hline $\begin{array}{c}\text { Karligkiotis et al., } 2017 \\
\text { [16] }\end{array}$ & 84 & 1996-2013 & 16 & 10 & 16 & $2(12.5)$ \\
\hline Gulsen et al., 2017 [17] & 48 & 2000-2014 & 6 & na & 6 & na \\
\hline Brihaye et al., 2019 [18] & 36 & 1999-2015 & 4 & na & 4 & healing type I or II \\
\hline Moreddu et al., 2020 [24] & 114 & 1986-2016 & 20 & 10 & na & na \\
\hline Our study, 2021 & 67 & 2001-2016 & 16 & 16 & 16 & $5(31.3)$ \\
\hline
\end{tabular}

CA, choanal atresia; na, not available. ${ }^{*}$ Revision surgery for restenosis after endoscopic CA repair. 
Schraff et al. first compared postoperative outcomes in 14 CHARGE patients (nine with bilateral CA and five with unilateral CA), treated via transnasal (10 cases) or transpalatal (four cases) approaches. The authors supported the primary transpalatal approach for patients with bilateral atresia [13]. Hengerer et al. included in their analysis 16 patients treated with transpalatal (11 procedures), transnasal (seven procedures), and endoscopic approaches (seven procedures). They confirmed the superiority of the endoscopic technique to reduce the risk of restenosis in CHARGE children [14]. The largest sample of CHARGE patients (20 cases) was collected in a study by Moreddu et al. [24]. They analyzed patients with both bilateral and unilateral CA (114 cases) treated surgically with different techniques (transpalatal and endoscopic with or without stent placement) at a single institution during 30 years of experience. Unfortunately, the authors did not differentiate outcomes adjusting for the diagnosis of CHARGE association. Interestingly, however, they observed a correlation between CHARGE association and an increased number of surgical interventions (2.85 vs. 2.16; $p=0.02$ ) [21]. Sinha et al. used Hegar's dilators and nasal stents in 22 cases. In their experience, CHARGE association had a very unsolicited outcome. All CHARGE patients (eight cases) died 5-10 days after surgery due to complications of the syndrome [15]. A recent Italian multicentric study included 84 patients with CA. The endoscopic technique was applied for all patients and a stent was placed at the beginning of the experience in some unilateral CA cases [16]. Sixteen were affected by CHARGE association (10 bilaterally and six unilaterally), and two of them (both bilateral) required revision surgery. Gulsen et al. collected six CHARGE children without mention of outcomes. Intriguingly, the authors concluded that the presence of congenital malformation associated with the atresia is one of the negative predictors for the successful rate of endoscopic repair [17]. The study of Brihaye showed good postoperative outcomes for the four CHARGE patients that demonstrated healing type I (normal healing) or II (limited scar formation and no breathing impairment) during follow-up [18].

The success rate adjusted for the use of a stent obtained in this study in CHARGEassociated CA was higher for non-stented patients $(83.3 \%)$ than stented patients $(60.0 \%)$, even if the difference was not statistically significant. Analogously to what was observed in the population with non-syndromic CA, also in the CHARGE population, patients treated without a stent needed a higher mean number of postoperative endonasal toilette procedures per patient, thus underlining the importance of adequate postoperative care to avoid concentric fibrosis and restenosis when a stent is not indicated.

There are several weaknesses in this study. The retrospective nature of the study did not allow us to standardize treatments and postoperative procedures. Prospective studies should implement the level of evidence on this topic, but the extremely low incidence rate of this clinical represents a limitation. Moreover, this study presented a lack of information on the prognostic role of the different surgical endoscopic methods applied for CA repair, which was beyond the scope of the paper. Further research should investigate the efficacy of the mucoperiosteal flap technique in surgical CA correction. Although the study population was too small to make definitive conclusions, the main strengths of the present study lie in the homogeneous series of consecutive patients included, and - probably for the first timein the investigation on the role of stent in postoperative outcomes for CHARGE patients.

\section{Conclusions}

Children with CHARGE association and bilateral CA benefit from endonasal endoscopic correction of the atretic plate, showing comparable results to that observed for non-syndromic-associated bilateral CA. Endonasal stent positioning led to the need for a significantly higher number of postoperative dilation procedures per patient in the nonsyndromic cohort. Although not statistically significant, data regarding stent application both in CHARGE and non-syndromic children revealed a higher rate of restenosis. Conversely, a higher number of endonasal toilette procedures per patient was registered in non-stented patients, thus underlying the need for meticulous postoperative care when endoscopic stent-free CA correction is preferred. 
Author Contributions: Conceptualization, M.B., D.C. and E.E.; methodology, M.B., D.C., and E.E.; software, M.B., D.C. and E.E.; validation, M.B., D.C., C.Z., G.F., A.S., F.P., S.P. and E.E.; formal analysis, M.B., D.C. and E.E.; investigation, M.B., D.C., and E.E.; resources, M.B., D.C., C.Z., G.F. and E.E.; data curation, M.B., D.C., C.Z. and E.E.; writing-original draft preparation, M.B. and D.C.; writing-review and editing, M.B., D.C., C.Z., G.F., A.S., F.P., S.P. and E.E.; visualization, M.B., D.C., C.Z., G.F., A.S., F.P., S.P. and E.E.; supervision, M.B., D.C., C.Z., G.F., A.S., F.P., S.P. and E.E.; project administration, M.B., D.C. and E.E. All authors have read and agreed to the published version of the manuscript.

Funding: This research received no external funding.

Institutional Review Board Statement: This study was conducted according to the guidelines of the Declaration of Helsinki.

Informed Consent Statement: Informed consent was obtained from all subjects involved in the study.

Data Availability Statement: The data presented in this study are available on request from the corresponding author.

Acknowledgments: This publication forms part of the degree thesis of the first author (M.B.).

Conflicts of Interest: The authors declare no conflict of interest.

\section{References}

1. Hall, B.D. Choanal atresia and associated multiple anomalies. J. Pediatr. 1979, 95, 395-398. [CrossRef]

2. Hittner, H.M.; Hirsch, N.J.; Kreh, G.M.; Rudolph, A.J. Colobomatous microphthalmia, heart disease, hearing loss, and mental retardationa syndrome. J. Pediatr. Ophthalmol. Strabismus. 1979, 16, 1228. [CrossRef]

3. Pagon, R.A.; Graham, J.M., Jr.; Zonana, J.; Yong, S.L. Coloboma, congenital heart disease, and choanal atresia with multiple anomalies: CHARGE association. J. Pediatr. 1981, 99, 223-227. [CrossRef]

4. Hale, C.L.; Niederriter, A.N.; Green, G.E.; Martin, D.M. Atypical phenotypes associated with patogenic CHD7 variants and a proposal for broedening CHARGE syndrome clinical diagnostic criteria. Am. J. Med. Genet. A 2016, 170A, 344-354. [CrossRef]

5. Zentner, G.E.; Layman, S.W.; Martin, D.M.; Scacheri, P.C. Molecular and phenotypic aspects of CHD7 mutation in CHARGE syndrome. Am. J. Med. Genet. A 2010, 152, 674-686. [CrossRef]

6. Jongmans, M.C.; Admiral, R.J.; van der Donk, K.P.; Vissers, L.E.L.M.; Baas, A.F.; Kapusta, L.; van Hagen, J.M.; Donnai, D.; de Ravel, T.J.; Veltman, J.A.; et al. CHARGE syndrome: The phenotypic spectrum of mutation in the CHD7 gene. J. Med. Genet. 2006, 43, 306-314. [CrossRef]

7. Hudson, A.; Macdonald, M.; Blake, K. Packing and Problematic Feeding Behaviors in CHARGE Syndrome: A Qualitative Analysis. Int. J. Pediatr. Otorhinolaryngol. 2016, 82, 107-115. [CrossRef]

8. Blake, K.D.; Prasad, C. CHARGE syndrome. Orphanet J. Rare Dis. 2006, 1, 34. [CrossRef]

9. Morgan, D.; Bailey, M.; Phelps, P.; Bellman, S.; Grace, A.; Wyse, R. Ear-Nose-Throat Abnormalities in the CHARGE Association. Arch. Otolaryngol. Head Neck Surg. 1993, 119, 49-54. [CrossRef]

10. Hsu, P.; Ma, A.; Wilson, M.; Williams, G.; Curotta, J.; Munns, C.F.; Mehr, S. CHARGE syndrome: A review. J. Paediatr. Child Health 2014, 50, 504-511. [CrossRef]

11. Bovo, R.; Trevisi, P.; Zanoletti, E.; Cazzador, D.; Volo, T.; Emanuelli, E.; Martini, A. New trends in rehabilitation of children with ENT disorders. Acta Otorhinolaryngol. Ital. 2017, 37, 355-367. [CrossRef]

12. Moreddu, E.; Rizzi, M.; Adil, E.; Balakrishnan, K.; Chan, K.; Cheng, A.; Daniel, S.J.; de Alarcon, A.; Hart, C.; Hartnick, C.; et al. International Pediatric Otolaryngology Group (IPOG) consensus T recommendations: Diagnosis, pre-operative, operative and post-operative pediatric choanal atresia care. Int. J. Pediatr. Otorhinolaryngol. 2019, 123, 151-155. [CrossRef]

13. Schraff, S.A.; Vijayasekaran, S.; Meinzen-Derr, J.; Myer, C.M. Management of choanal atresia in CHARGE association patients: A retrospective review. Int. J. Pediatr. Otorhinolaryngol. 2006, 70, 1291-1297. [CrossRef]

14. Hengerer, S.; Brickman, T.M.; Jeyakumar, A. Choanal Atresia: Embryologic Analysis and Evolution of Treatment, a 30-Year Experience. Laryngoscope 2008, 118, 862-866. [CrossRef]

15. Sinha, V.; Talagauara Umesh, S.; Jha, S.G.; Dadhich, S. Choanal Atresia: Birth Without Breath. Indian J. Otolaryngol. Head Neck Surg. 2018, 70, 53-58. [CrossRef]

16. Karligkiotis, A.; Farneti, P.; Gallo, S.; Pusateri, A.; Zappoli-Thyrion, F.; Sciarretta, V.; Pagella, F.; Castelnuovo, P.; Pasquini, E. An Italian multicentre experience in endoscopic endonasal treatment of congenital choanal atresia: Proposal for a novel classification system of surgical outcomes. J. Cranio-Maxillofac. Surg. 2017, 45, 1018-1025. [CrossRef]

17. Gulsen, S.; Baysal, E.; Celenk, F. Treatment of Congenital Choanal Atresia via Transnasal Endoscopic Method. J. Craniofac. Surg. 2017, 28, 338-342. [CrossRef]

18. Brihaye, P.; Delpierre, I.; De Villé, A.; Johansson, A.B.; Biarent, D.; Mansbach, A.L. Comprehensive management of congenital choanal atresia. Int. J. Pediatr. Otorhinolaryngol. 2017, 98, 9-18. [CrossRef]

19. Stankiewicz, J.A. The endoscopic repair of choanal atresia. Otolaryngol. Head. Neck Surg. 1990, 103, 931-937. [CrossRef] 
20. Park, A.H.; Brockenbrough, J.; Stankiewicz, J. Endoscopic versus traditional approaches to choanal atresia. Otolaryngol. Clin. N. Am. 2000, 33, 77-90. [CrossRef]

21. Bedwell, J.R.; Choi, S.S. Are Stents Necessary After Choanal Atresia Repair? Laryngoscope 2012, 122, 2365-2366. [CrossRef]

22. Strychowsky, J.E.; Kawai, K.; Moritz, E.; Rahbar, R.; Adil, E.A. To Stent or Not to Stent? A Meta-analysis of Endonasal Congenital Bilateral Choanal Atresia Repair. Laryngoscope 2016, 126, 218-227. [CrossRef]

23. Tomoum, M.O.; Askar, M.H.; Mandour, M.F.; Amer, M.A.; Saafan, M.E. Stentless mirrored L-shaped septonasal flap versus stented flapless technique for endoscopic endonasal repair of bilateral congenital choanal atresia: A prospective randomised controlled study. J. Laryngol. Otol. 2018, 132, 329-335. [CrossRef]

24. Moreddu, E.; Rossi, M.E.; Nicollas, R.; Triglia, J.M. Prognostic Factors and Management of Patients with Choanal Atresia. J. Pediatr. 2019, 204, 234-239. [CrossRef] 